\title{
Causalidade e necessidade na ontologia de Espinosa
}

\author{
Luís César Guimarães Oliva
}

Universidade de São Paulo 

A causalidade é em Espinosa o elemento fundamental para a compreensão do real em todas as suas manifestações. Adepto do adágio aristotélico "conhecer é conhecer pela causa", o filósofo, contudo, faz uma considerável reforma na noção aristotélica de causalidade, reforma na qual se destaca, antes de tudo, a crítica da causa final.

Ora, Aristóteles, ao elaborar a teoria das quatro causas (formal, eficiente, material e final), propunha a finalidade como elemento preponderante da causalidade, na medida em que, a partir do fim, compreendia-se todo o processo causal. De fato, a causa final aristotélica confunde-se com a formal, pois o fim nada mais é que a plena atualização da forma ou essência que define a natureza da coisa'. É como finalidade que a forma será aplicada à matéria, apropriando-se desta conforme o ideal visado²; e é também através do fim que os instrumentos adequados são determinados 3 , de modo que o agente só é causa eficiente na medida em que possui a forma ou modelo como fim. Tal imbricamento dos tipos de causa sob o comando da causa final fará com que uma crítica radical da finalidade implique uma revisão da concepção de causa em geral.

Já antes de Espinosa, no entanto, os modernos começaram a contestar esse quadro. Bacon valorizava sobretudo a causa for-

1 Veja-se, por exemplo, os traços finalistas da seguinte apresentação da forma:"Pois o naturado, enquanto está sendo naturado, vai de um termo a outro. Em direção a qual? Não é para o ponto de partida; é em direção àquilo a que ele tende, isto é, a forma; portanto é a forma que é natureza" (Aristóteles, 1961, p. 62). E mesmo uma identificação mais explícita: "Ademais, a natureza sendo dupla, matéria de um lado, forma do outro, e esta sendo fim e as outras em vista deste fim, esta será uma causa, a causa final" (Ibid., p. 78).

2 "Por que a serra é assim? Para isto e em vista disto; ora, este fim não pode produzir-se se a serra não é de ferro; portanto necessariamente ela é de ferro se se quer que haja uma serra e sua operação". (Ibid., II, 9, 200a 7-12)

3 "Bem entendido, pertence também a essa mesma causalidade [final] tudo o que, movido por outra coisa diferente de si, é intermediário entre esse motor e o fim, por exemplo, para a saúde, o emagrecimento, a purgação, os remédios, os instrumentos; pois todas estas coisas são em vista do fim, e só diferem entre elas como ações e instrumentos". (Ibid., p. 65). 
mal: as causas material e eficiente eram apenas veículos para as formas. Já a causa final não tinha lugar em seu projeto de ciência. Ela poderia encontrar-se na Religião ou na Ética, mas na ciência era perversa, visto que ocultava as verdadeiras causas físicas. Dizer que existem folhas nas árvores "para proteger os frutos", ou nuvens "para regar a terra" nada dizia sobre o verdadeiro processo causal almejado pela ciência baconiana. O finalismo, porém, ainda não tinha encontrado seu mais duro adversário: Espinosa.

O que diz Espinosa sobre a finalidade? "Todos os preconceitos que aqui me incumbo de denunciar dependem de um único, a saber, todos os homens comumente supõem que as coisas naturais agem, como eles próprios, em vista de um fim; mais ainda, dão por assentado que o próprio Deus dirige todas as coisas para algum fim certo..." (Espinosa, 2015, p. 111). No sistema espinosano, a causa final é não apenas recusada, mas é vista como núcleo e origem dos preconceitos que impedem a plena aceitação das demonstrações efetuadas. E o que foi demonstrado na parte I da Ética?

A natureza de Deus e suas propriedades, tais como: que existe necessariamente; que é único, que é e age pela só necessidade de sua natureza; que é a causa livre de todas as coisas e como o é; que tudo é em Deus e depende dele de tal maneira que sem ele nada pode ser nem ser concebido; e, finalmente, que tudo foi predetermindado por Deus, não decerto pela liberdade da vontade, ou seja, por absoluto beneplácito, mas pela natureza absoluta de Deus, ou seja, por sua potência infinita (Ibid., p. 109).

Portanto, o que o preconceito finalista, como fonte primeira de todos os preconceitos, impede de aceitar, é toda a ontologia espinosana, base da teoria do conhecimento, da doutrina das paixões e das concepções de servidão e liberdade que virão a seguir no livro. Por isso, a visão finalista da realidade é, segundo o filósofo, incompatível com sua filosofia, sendo-lhe forçoso refutá-la impiedosamente. Não bastava reservar para a causa final um espaço 
limitado (como fizera Bacon, limitando-a à Religião e à Ética). Era preciso bani-la em definitivo.

No apêndice da parte I da Ética, Espinosa propõe-se a fazê-lo, mostrando a origem desse preconceito bem como a sua falsidade. Para isso, o filósofo não pede ao leitor senão que reconheça dois fatos de que, diz ele, ninguém duvidará: “todos os homens nascem ignorantes das causas das coisas, e que todos têm o apetite de buscar o que lhes é útil, sendo disto conscientes" (Ibid., p. 111). Ora, o que faz Espinosa é aplicar um dado sobre o outro, extraindo a seguinte conclusão: conscientes do desejo do que lhes é útil, mas ignorantes das causas desse mesmo desejo, os homens fazem daquele útil a "causa final" de suas ações. Daí a projetar tais causas finais para toda a natureza, é um salto que a imaginação humana dá sem maiores dificuldades, como veremos agora. Esses mesmos homens que se guiam por "fins" criam meios para obtê-los. Criam, por exemplo, ferramentas para separar e unir objetos, e assim por diante. Contudo, também encontram na natureza inúmeras coisas que eles não criaram, mas que lhes servem como meios para alcançar seus fins: por exemplo, olhos para ver, dentes para mastigar, alimentos para comer etc. Por isso creem, contaminados pela visão finalista, que haveria outro Ser, regente da natureza, que tudo criou visando beneficiar os homens, e estes, por sua vez, para cultuá-lo.

Está assim criada uma máquina imaginativa da qual o homem não pode mais sair e que faz da busca pela causa uma busca, de fato, pela ignorância, a cada passo mais profunda, que culmina com a renúncia completa à busca das causas. Como essa

4 "Com efeito, depois que consideraram as coisas como meios, não puderam crer que se fizeram a si mesmas, mas a partir dos meios que costumam prover para si próprios tiveram de concluir que há algum ou alguns dirigentes da natureza, dotados de liberdade humana, que cuidaram de tudo para eles e tudo fizeram para o seu uso. E visto que nada jamais ouviram o engenho destes, tiveram também de julgá-lo pelo seu e, por conseguinte, sustentaram que os Deuses dirigem tudo para o uso dos homens a fim de que estes lhes fiquem rendidos e lhes tributem suma hora" (Espinosa, 2015, , Pp. 111-112). 
renúncia se apresenta? Paradoxalmente, como a vontade arbitrária de Deus. Mal comparando, trata-se do velho "Porque Deus quis!" que todos já respondemos alguma vez a alguma criança curiosa que não se satisfez com nossas respostas. Em nosso mundo, permeado pela visão finalista, Deus torna-se, nas palavras de Espinosa, o "asilo da ignorância"s. Exatamente o oposto do que será o Deus espinosano, que através de seus atributos constitui a inteligibilidade do real.

Para o filósofo, não é o útil que atua como o fim de que carecemos e que nos atrai e dirige. Na verdade, é o próprio desejo do útil a causa eficiente da busca de determinados bens. Este desejo, por sua vez, é um movimento com uma determinada direção, movimento que tem efeitos e causas, e estas últimas têm outras causas que, por sua vez, têm outras, e assim ao infinito, mas sempre a partir da eficiência, nunca da finalidade. Espinosa não quer apenas denunciar que o homem antropomorfiza a natureza e Deus, ao dizer que se guiam por fins. Mais do que isso, o filósofo mostra que o próprio homem não se guia por fins, a não ser enquanto se ilude.

Vejamos agora qual é a posição de Espinosa em relação à causa formal, tão destacada por Bacon. Na tradição, a causa for-

5 "Nem há que silenciar aqui que os Seguidores dessa doutrina, que quiseram dar mostras de seu engenho assinalando fins para as coisas, a fim de prová-la tenham introduzido um novo modo de argumentar, a saber, não a redução ao impossível, mas à ignorância, o que mostra não ter havido para essa doutrina nenhum outro meio de argumentar. Com efeito, por exemplo, se uma pedra cair de um telhado sobre a cabeça de alguém e o matar, demonstrarão do seguinte modo que a pedra caiu para matar esse homem: de fato, se não caiu com este fim e pelo querer de Deus, como é que tantas circunstâncias (pois amiúde muitas concorrem simultaneamente) puderam concorrer por acaso? Responderás talvez que isso ocorreu porque soprou um vento e o homem fazia seu caminho por ali. Insistirão, porém: por que o vento soprou naquele momento? por que o homem fazia o caminho por ali naquele mesmo momento? Se, ainda uma vez, responderes que o vento se levantou na ocasião porque, na véspera, quando o tempo ainda estava calmo, o mar começara a agitar-se, e porque o homem fora convidado por um amigo, insistirão novamente, porquanto o perguntar nunca finda: por que o mar se agitara? por que o homem fora convidado naquela ocasião? E assim, mais e mais, não cessarão de interrogar pelas causas das causas, até que te refugies na vontade de Deus, isto é, no asilo da ignorância” (Ibid., pp. 115-117). 
mal é, de maneira privilegiada, a que diz o que uma coisa é. A forma é a ideia da coisa, aquilo que, separado ou não da própria coisa, permitirá distingui-la das outras coisas e assim dará ao real a possibilidade de ser inteligível. Ora, sendo assim, a forma será decisiva para a definição, já que definir nada mais é do que dizer o que uma coisa é. Como era então a teoria da definição na tradição a que se oporá Espinosa, tradição cuja base era a lógica aristotélica? Grosso modo, as definições eram feitas por gênero e diferença. Tomemos, por exemplo, o homem: este ser enquadra-se no gênero maior dos animais e diferencia-se especificamente pela racionalidade. É isso que está por trás da definição clássica de homem como animal racional. Tal definição evidentemente não esgota as propriedades do homem (poder-se-ia dizer que ele é bípede, implume, etc.), mas basta não apenas para delimitar a espécie como também para dizer o que constitui essencialmente um homem (ver Aristóteles, 1962, pp. 212-225).

Espinosa não negará a possibilidade de se fazer uma definição desse tipo, porém ela não será considerada uma definição perfeita. Baseando-se mais na matemática do que na lógica tradicional, o filósofo fará da definição uma apresentação da origem causal da coisa em questão, da qual brotarão todas as propriedades da coisa, sejam aquelas tidas pela tradição como essenciais (no caso do homem, o pensar), sejam as acidentais (ser bípede). A definição perfeita espinosana será portanto genética. O exemplo que o filósofo usa é o círculo: a definição mais comum diz que círculo é a figura em que todos os pontos são equidistantes do centro. Para Espinosa, no entanto, trata-se apenas de uma propriedade do círculo. A definição perfeita do círculo deverá abranger a causa eficiente, a saber, o círculo é uma figura descrita por uma linha com uma extremidade fixa e outra móvel. Este movimento da linha em torno do centro fixo "construirá" geometricamente o referido círculo e será a causa eficiente dele (ver Espinosa, 1973, p. 72).

À primeira vista, poderíamos dizer que a definição por gênero e diferença diz o que a coisa é, enquanto a definição genética diz 
como ela foi feita. Em outras palavras, a primeira definiria pela causa formal, enquanto a segunda definiria pela causa eficiente. Isso seria, contudo, uma grosseira simplificação da revolução operada por Espinosa em relação à tradição. Como diz Marilena Chaui,

A definição perfeita espinosana exige que a estrutura íntima da coisa ou sua causa próxima sejam oferecidas, porém a causa eficiente interna é a própria causa formal, pois entre uma essência particular e sua causa próxima interna não há diferença. (Chaui, 1999, p. 662, grifo nosso)

Ora, isso significa que a essência do círculo é o movimento mesmo de sua construção, ou seja, causa formal e causa eficiente se identificam necessariamente. Por isso a definição perfeita só poderá ser genética. Como consequência, toda a teoria espinosana do conhecimento se baseará na causa eficiente (que agora abrange também a causa formal). Conhecer é ainda, como para Aristóteles, conhecer pela causa, mas o sentido da afirmação mudou por completo.

A partir desse cenário podemos abordar a causa de si, conceito apresentado na definição de abertura da Ética e que domina todo o livro. A causalidade eficiente, tal como a descrevemos, deve dar conta dessa noção. No entanto, a tradição colocava sérias dúvidas quanto à possibilidade de uma causa eficiente de si, como mostram as Primeiras e Quartas Objeções e respostas às Meditações de Descartes. Discutindo as provas da existência de Deus da Terceira Meditação, Caterus levanta a questão da aseidade divina. Se Deus for por si (a se) nos termos da tradição tomista, será por si como sem causa, ou seja, a aseidade divina será entendida negativamente, o que condenará a demonstração cartesiana, pois o que não tem causa não é obrigatoriamente infinito, podendo ser limitado por sua constituição interna. Arnauld, por sua vez, aprofundará a crítica de Caterus. Diante da resposta cartesiana de que a aseidade divina é positiva, como por uma causa, Arnauld aponta algumas contradições: 
De fato, todo efeito sendo dependente de sua causa, e recebendo dela o seu ser, não é assaz evidente que uma mesma coisa não pode depender nem receber o ser de si mesma? E mais, se toda causa é a causa de um efeito, e todo efeito é o efeito de uma causa, há portanto uma relação mútua entre a causa e o efeito. Ora, não pode haver relação mútua senão entre duas coisas. Além disso, não se pode conceber, sem absurdo, que uma coisa receba o ser e contudo essa mesma coisa tenha o ser antes que tenhamos concebido que o recebeu. Ora, é isso o que ocorreria, se atribuíssemos as noções de causa e efeito a uma mesma coisa em relação a si mesma. Pois qual é a noção de uma causa? Dar o ser. Qual a noção de um efeito? Recebê-lo. Ora, a noção da causa precede naturalmente a noção do efeito; e não podemos conceber uma coisa sob a noção de causa, como dando o ser, se não concebemos que ela o tem, pois ninguém pode dar algo que não possui. Logo, conceberíamos antes que uma coisa tem o ser do que conceberíamos que ela o recebeu; e contudo, nisto que recebe, receber precede o possuir. Essa razão pode ser ainda explicada assim: ninguém dá o que não possui; logo, ninguém pode dar-se o ser, senão aquele que já o tem; ora, se já o tem, por que o daria a si mesmo? (Arnauld, apud Descartes 1999, p. 647)

Efetivamente, Descartes reconhecera, nas respostas a Caterus, a possibilidade da causa eficiente de si que tantas críticas receberia de Arnauld:

Por fim, eu não disse que é impossível que uma coisa seja causa eficiente de si mesma, pois ainda que isso seja manifestamente verdadeiro quando se restringe a significação de eficiente às causas que são diferentes de seus efeitos ou que os precedem no tempo, parece todavia que nesta questão não se deve restringir desta maneira, tanto porque seria uma questão frívola (pois quem não sabe que uma mesma coisa não pode ser diferente de si mesma nem se preceder no tempo?), quanto porque a luz natural não nos dita que seja próprio da causa eficiente preceder temporalmente seu efeito. (Descartes, 1999, p. 527) 
Diante das objeções mais genéricas de Caterus, Descartes não vê dificuldade em reduzir a impossibilidade lógica detectada pelo tomista na causa de si a uma mera incompatibilidade temporal que só afeta uma parcela da causalidade eficiente. A bem da verdade, dirá Descartes, a exigência de precedência temporal da causa em relação ao efeito desconsidera que a causalidade propriamente dita, enquanto se realiza, é o que determina a causa, e não vice-versa, ou seja, que antes da ação causal uma causa sequer é causa. O que o filósofo deixa de lado inicialmente é o verdadeiro motivo de escândalo, a imanência causal contida na causa de si e apenas discretamente citada no trecho acima. $\mathrm{O}$ acento, nesse momento, é no alcance epistêmico da pergunta pela causa: "é verdade que a luz natural nos dita que não há nenhuma coisa da qual não seja possível perguntar por que existe, ou de que não se possa buscar a causa eficiente, ou bem, se não a possui, perguntar por que não precisa dela”. (Ibid., p. 527).

Se o resultado da inquirição causal fosse um ente não causado, ou seja, apenas negativamente a se, não só o mecanismo de prova cartesiano entraria em colapso, como a ininteligibilidade se colocaria, de direito, no início do percurso de conhecimento. A universalidade e mesmo o fundamento ontológico do princípio de razão suficiente estão em jogo, e por isso Descartes deve reconhecer

que pode haver alguma coisa na qual haja uma potência tão grande e tão inesgotável que ela jamais tenha precisado de auxílio para existir, e que não tenha ainda necessidade disso agora para ser conservada, e que assim seja de algum modo a causa de si mesma; e concebo que Deus é tal coisa. (Ibid., p. 528)

Essa positividade do Deus a se, que implica a causa eficiente de si como fonte de inteligibilidade para o real, será no entanto relativizada, reduzida a uma analogia da causa eficiente das coisas: 
“é-nos de fato possível pensar que ele faz de algum modo a mesma coisa para consigo mesmo que a causa eficiente para com seu efeito; e portanto que ele é por si positivamente" (Ibid., p. 530). As razões desse recuo aparecerão mais claramente nas respostas a Arnauld. Instado pelo jansenista, Descartes reconhece a precariedade do conceito de causa eficiente de si, ressaltando o caráter analógico de suas afirmações. A pergunta pela causa eficiente deve ter abrangência universal, incluindo Deus, e sua resposta deve ser sempre positiva, mesmo para Deus. Todavia, isso não significa que esse positivo deva ser, ele mesmo, uma causa eficiente no mesmo sentido que se usa esse termo para as coisas. A resposta à pergunta pela causa eficiente pode ser uma razão pela qual a coisa não precisa de causa eficiente, desde que essa razão seja algo positivo, que garanta a universalidade do princípio. No caso das criaturas, que são por outro, a resposta é a própria causa eficiente. No caso de Deus, que é por si, a razão será não a causa eficiente, mas a imensidão de potência contida na essência divina. O resultado disto é que Descartes, diante da pergunta pela causa eficiente, deve terminar com uma resposta pela causa formal:

E assim, em todos os outros lugares, de tal modo eu comparei a causa formal, ou a razão tomada da essência de Deus, pela qual ele não precisa de causa para existir nem para ser conservado, com a causa eficiente, sem a qual as coisas finitas não podem existir, que em toda parte é fácil conhecer, por meus próprios termos, que ela é totalmente diferente da causa eficiente. (Ibid., p. 679)

Tal alteração, porém, não muda a lógica causal das respostas, já que a causa formal está para Deus assim como a causa eficiente está para as criaturas. A ratio é a mesma, apesar do hiato que separa a causalidade das coisas finitas da causalidade da coisa infinita. Por isso Descartes, sem chegar à identificação de Espinosa (que suprime esse hiato), pode fazer uma curiosa aproximação das duas causas: 
Todos aqueles que seguem somente a conduta da luz natural formam rapidamente nessa ocasião certo conceito, que participa da causa eficiente e da formal, e que é comum a uma e outra: a saber, que o que é por outro é por ele como por uma causa eficiente; e o que é por si é como por uma causa formal, quer dizer, porque tem uma natureza tal que ele não precisa de causa eficiente. (Ibid., p. 68z)

Sem igualar-se a ela, a causa formal ou essência positiva da coisa será o limite da causa eficiente, assim como um círculo pode ser visto como polígono de infinitos lados.

Como explica Chaui, é esta a diferença, embora Descartes pudesse vê-la como infinitesimal, que o separa de Espinosa:

A matemática oferecera a Espinosa o primeiro exemplo de identidade entre causa formal e causa eficiente interna (toda coisa deve ter uma causa determinada (data) e toda causa determinada é a razão interna da coisa), de sorte que não seria possível falar em analogia da eficiente à formal, pois são uma só e mesma causa; estamos no campo da univocidade, no qual definições sustentam demonstrações potissimae. Isso significa que toda essência é uma potência de existir e de agir e que, por conseguinte, a essência e sua natureza são uma só e mesma atividade. (Chaui, 1999, p. 782)

Limitando a aproximação das causas formal e eficiente a uma analogia, Descartes separa essência e potência divinas, e com isso insere um intervalo (por menor que seja) entre essência e existência, o qual só será sanado pela ação da potência divina contida na essência. Em Espinosa, tal intervalo não existe, e por isso não há por que demarcar sentidos diversos para a causalidade eficiente em Deus e nas coisas. Ao contrário, Deus será causa eficiente da essência e da existência das coisas no mesmo sentido em que é causa de si: "com efeito, desta proposição (16) segue que da natureza divina dada deve concluir-se necessariamente tanto a essência quanto a existência das coisas; e, em uma palavra, no sentido 
em que Deus é dito causa de si, é a dizê-lo também causa de todas as coisas". (Espinosa, 2015, p. 91, grifo nosso)

A proposição 16, evocada por este último escólio, tem como primeiro corolário que Deus é causa eficiente de todas as coisas que podem cair sob um intelecto infinito, ou seja, aquele "sentido" é o da eficiência. Eficiência transitiva? Diriam que sim, os que objetam a Descartes, certos de que seria esse o único sentido de eficiência compatível com a lógica tradicional. Mas não Espinosa. Como causa de si que se autoproduz ao produzir todo o resto em sua própria substância, Deus só poderá ser causa eficiente imanente:

A distinção entre causa eficiente imanente e causa eficiente transitiva significa que a eficiente não é tomada como causa externa artesanal, e sim como causa interna. A eficiente transitiva pressupõe não só a separação entre causa e efeito e a dessemelhança entre ambos, como ainda o caráter instantâneo da causa (como tão bem lembrara Descartes a Arnauld, uma coisa recebe o nome de causa eficiente no ato de causar o efeito). A eficiente imanente, ao contrário, afirma que a causa e o efeito não se separam e que o segundo é a própria causa modificada ou, para mantermos a precisão conceitual de Espinosa, ele a exprime e ela o envolve. (Chaui, 1999, p. 874)

A ação causal imanente demonstrada na proposição 18 "Deus é causa imanente de todas as coisas mas não transitiva" (Espinosa, 2015, p. 81) - significa a imanência de Deus aos seus efeitos, ou seja, faz deles (a saber, da totalidade das coisas) afecções dos atributos divinos. Isto será afirmado explicitamente no corolário da proposição 25: "As coisas particulares nada são senão afecções dos atributos de Deus, ou seja, modos pelos quais os atributos de Deus se exprimem de maneira precisa e determinada" (Ibid., p. 91). Entretanto, tal afirmação não invocará a causalidade imanente de Deus, mas sim a condição primeira de sua possibilidade, demonstrada na proposição 15 (Ibid., pp. 67-69). Nesta 
última, Espinosa partia da unicidade substancial já demonstrada e da definição de modo como um "por outro" para concluir que "tudo que é, é em Deus, e nada sem Deus pode ser nem ser concebido" (Ibid.). Assim é a partir da imanência das coisas a Deus, decorrência necessária da unicidade substancial, que Espinosa deduzirá, na proposição 18 (Ibid., pp. 81-83) a imanência de Deus às coisas. Não se trata, porém, de redundância, pois a inversão dos termos é intermediada pela demonstração, na proposição 16 (Ibid., p. 75) de que da necessidade da natureza divina devem seguir infinitas coisas em infinitos modos. Esta demonstração se apoia na já referida teoria da definição perfeita, mas aqui o acento não vai para o caráter genético da definição e sim para os efeitos que necessariamente decorrem da definição causal. Em outras palavras, o que interessa aqui é como a essência afirmada causalmente na definição se desdobra em potência de produzir efeitos ou propriedades proporcionais à essência. Dada a definição de Deus ("por Deus entendo o ente absolutamente infinito, isto é, a substância que consiste em infinitos atributos, cada um dos quais exprime uma essência eterna e infinita" [Ibid., p. 45]), é evidente que sua essência (infinitos atributos infinitos) envolverá uma realidade infinita, ou seja, dela deve seguir tudo que existe, seja essência ou existência. Daí decorre o corolário já citado em que se estabelece a eficiência universal da essência divina. Devemos concluir que para Espinosa a imanência das coisas a Deus (proposição 15) e a eficiência universal (proposição 16) conjugam-se para fazer da causa eficiente imanente (proposição 18) a força estruturante e produtora do real, mesmo que na Ética as proposições posteriores não evoquem diretamente a proposição 18 e sim as proposições que a condicionam. Logo, não há redundância na passagem da imanência das coisas a Deus à imanência de Deus às coisas, e sempre que houver recurso simultâneo às proposições 15 (imanência das coisas a Deus) e 16 (eficiência universal), deve entender-se que a causalidade eficiente imanente (proposição 18) está em ação. 
No escólio da proposição 15, Espinosa critica aqueles que separam extensão e natureza divina, sustentando ser aquela uma substância criada por Deus. Por qual potência Deus pôde criá-la, porém, ignoram. Mas essa ignorância não é reflexo senão dos limites da causalidade transitiva, a qual já tornara incompreensível para nós o Deus cartesiano. De fato, como Descartes havia generalizado o princípio de razão a partir da causa eficiente, a resposta analógica no caso do próprio Deus abre uma brecha, senão de ininteligibilidade, ao menos de incompreensibilidade, ilustrada pela distinção entre entender e compreender. Isto faz que entendamos a superabundância de potência divina como causa do que existe, sem contudo compreendermos como opera precisamente essa causalidade, devido à distância que separa a finitude de nosso entendimento e a infinitude divina. A mesma ignorância estava implicada na proposição 6 (Ibid., p. 51), onde se demonstrava que uma substância não pode ser produzida por outra, ou seja, que não há, de direito, criação. Se uma substância pudesse ser produzida por outra, o conhecimento dela deveria depender do conhecimento daquela outra (pelo axioma 4 [Ibid., p. 47]). Contudo a substância espinosana é definida pela independência conceitual: sendo concebida por si mesma, perderia seu caráter substancial se tivesse sua inteligibilidade condicionada à de outra. Logo, a criação de uma substância por outra é um absurdo que destrói o próprio conceito de substância. Já aqui, portanto, a transitividade da ação divina será sinônimo de ininteligibilidade, ocultada pela incompreensibilidade em Descartes, que por sua vez é denunciada como ignorância no escólio da proposição 15 (Ibid., pp. 69-75)

A causa eficiente imanente será responsável por diluir essa ininteligibilidade, justamente na medida em que executa aquela identificação entre essência e potência da qual antes falamos, identificação contida na definição de causa de si, embora demonstrada apenas no final do primeiro livro. A partir da causalidade eficiente imanente, não é difícil perceber como a causa de si produzirá a totalidade do real e ao mesmo tempo garantirá sua 
plena inteligibilidade, em ambos os casos, como veremos, com absoluta necessidade.

Demonstrada a causalidade divina imanente, Espinosa parte para a demonstração da eternidade de Deus e de seus atributos (proposição 19 [Ibid., p. 83]). Como substância, Deus existe necessariamente (proposição 7 [Ibid., p. 53]). Este recurso à proposição 7 funciona como um apelo indireto à definição de causa de si, que a condiciona. Tendo provado na proposição 6 (Ibid., p. 51) que uma substância não pode ser produzida por outra coisa, só lhe resta ser causa de si mesma, o que, pela definição 1, significa que sua essência envolve a existência. Sob o domínio da causa de si, não é difícil encaminhar-se para a eternidade. Se não, vejamos: o envolvimento da existência significa que a ação própria da coisa é existir, ou seja, é a afirmação plenamente atual da existência. Deste modo, o ser mesmo da coisa é seu gerar-se como existente, o que faz com que a definição de causa de si cumpra os requisitos da definição perfeita. Porém a definição 8 enuncia: Por eternidade entendo a própria existência enquanto concebida seguir necessariamente da definição da só coisa eterna (Ibid., p. 47). Ora, nada mais claro do que o fato de que Deus, como causa sui, é eterno. Por outro lado, pela definição 4, sabemos que atributo é o que constitui a essência da substância. Sendo a essência de Deus eterna, por envolver a existência, é claro que seus constituintes também deverão ser eternos, já que envolvem o mesmo que ela. Portanto, os atributos divinos também são eternos.

Da eternidade de Deus e seus atributos, Espinosa demonstrará a identidade entre existência e essência divinas (proposição 20 [Ibid., p. 83] ). Se a eternidade é a própria existência que segue da essência da coisa eterna, é evidente que os atributos, ao exprimirem a essência divina, igualmente estão exprimindo a existência divina. Por isso, aquilo que constitui a essência divina, constitui pela mesma ação a existência divina. E como a essência divina não é senão esta ação de existir, é claro que essência e existência divinas são o mesmo. Disto decorrem duas consequências inter- 
dependentes: primeiro, que a existência e a essência divinas são uma verdade eterna; segundo, que Deus e seus atributos são imutáveis, pois, se mudassem quanto à existência, mudariam também quanto à essência (pois elas são o mesmo), o que as desmentiria como verdade eterna. Essa imutabilidade é fundamental para o sistema, já que, como diz Marilena Chaui,

a estrutura do universo não muda. Pelo contrário, ela é a condição para que haja mudanças ordenadas, reguladas e inteligíveis que nela se realizam segundo seus princípios imanentes. É este o sentido profundo da imanência: o de uma realidade autoproduzida ou absolutamente existente cuja essência é autodiferenciada e autorregulada, que subsiste em si e por si mesma e que é a ratio essendi e a ratio cognoscendi de todas as infinitas maneiras ou infinitas variações de suas infinitas modificações. (Chaui, 1999, p. 878)

Até aqui vimos a estrutura imutável do universo. As próximas proposições mostram como essa estrutura fixa se desdobra em modificações finitas e infinitas. Em outras palavras, depois de apresentar a causalidade imanente como força estruturante do real, resta a Espinosa apresentar os efeitos imanentes que preenchem a estrutura. O primeiro passo é a dedução dos modos infinitos. $\mathrm{Na}$ proposição 21, Espinosa afirma que "tudo que segue da natureza absoluta de um atributo de Deus deveu existir sempre e infinito, ou seja, pelo mesmo atributo é eterno e infinito" (Espinosa, 2015, p. 85). A demonstração se dá por redução ao absurdo: ela parte da hipótese de que da natureza absoluta de um atributo, ou seja, sem que o atributo seja afetado de nenhuma maneira, siga algo de finito, por ex. a ideia de Deus no pensamento. Vale lembrar que a hipótese não rompe a imanência, pois Espinosa refere-se a algo finito que siga em um atributo de Deus, e seu exemplo é aquela ideia. Como atributo de Deus, o pensamento é, por definição, infinito, mas a hipótese supõe que ele seja finito enquanto tem a ideia de Deus. A causalidade imanente imporia, no inte- 
rior da hipótese, que o atributo pensamento se tornasse finito, já que não há efeitos externos à causa. Por outro lado, a finitude se define pela limitação por uma outra coisa de mesma natureza, isto é, um corpo limita um corpo menor, mas um pensamento não limita um corpo. Desta maneira, aquele pensamento tornado finito, que constitui a ideia finita, deverá ser limitado pelo próprio pensamento, mas agora infinito e portanto não constituindo a ideia finita, o que contraria a hipótese. Demonstrada a infinitude necessária do modo infinito imediato (que segue da natureza absoluta do atributo), a demonstração da eternidade será análoga. Também análoga será a demonstração da infinitude e da necessidade do modo infinito mediato, ou seja, aquilo que segue de um atributo divino enquanto afetado por uma modificação infinita (proposição 22 [Ibid., p. 87]).

Enquanto as proposições 21 e 22 focavam a ação causal dos atributos, a proposição 23 (Ibid.) vai tomar a perspectiva do efeito para mostrar que as duas produções anteriormente descritas são as únicas possibilidades de causação dos modos infinitos. Nesse novo ponto de vista, Espinosa não precisará utilizar expressões como "o que quer que siga", e por isso usará diretamente "modo" ("Todo modo que existe necessariamente e infinito deveu necessariamente seguir ou da natureza absoluta de algum atributo de Deus, ou de algum atributo modificado por uma modificação que existe necessariamente e infinita" [Ibid.]). Mesmo sem ter aparecido nominalmente nas duas proposições anteriores, a modalidade era uma presença implícita, visto que a ação constituinte dos atributos sobre seus efeitos fazia destes necessariamente um "em outro”. Afinal, era dos atributos que tais coisas extraíam seu ser e sua inteligibilidade, já que o conhecimento do efeito depende do conhecimento da causa.

A demonstração da proposição 23 parte da definição de modo (a saber, aquilo que é em outro e concebido por outro) e da imanência das coisas a Deus (proposição 15) para mostrar que todo modo é em Deus e só se concebe por Deus. Se um modo é con- 
cebido como necessariamente existente e infinito, logicamente deve sê-lo por um atributo divino (já que o modo é por Deus) enquanto este é concebido exprimir a infinidade e a necessidade da existência, ou seja, a eternidade. Isso exclui que tal modo seja concluído de um atributo divino finitamente modificado, restando-lhe seguir da natureza absoluta de um atributo divino, seja imediatamente, seja mediante uma modificação infinita imediata. É interessante notar que, ao assumir a perspectiva do efeito, Espinosa valoriza o vocabulário da inteligibilidade ("ser concebido por”), destacando os efeitos cognitivos da causalidade imanente. O modo não é necessário pela essência (como a substância), mas pela causa. Assim, a dedução dos modos infinitos mostra como essa necessidade pela causa é uma expressão da necessidade (pela essência) da causa, e não o resultado de uma ação incompreensível de um Deus arbitrário.

As coisas particulares só aparecerão no já referido corolário da proposição 25, onde são apresentadas como afecções dos atributos de Deus, ou modos pelos quais eles se exprimem de maneira determinada. Como já explicamos, o apelo às proposições 15 ("Tudo que é, é em Deus" [Ibid., p. 67]) e 16 ("Da necessidade da natureza divina seguem infinitas coisas..." [Ibid., p. 75]) representa recurso à ação da causa eficiente imanente. Daí que essa particularização decorra da e na causa. Dada a natureza divina, todas as essências e existências devem seguir necessariamente, e isto evidentemente inclui também o finito. Mesmo sendo expressões determinadas dos atributos, as coisas particulares são produzidas pela mesma força causal com que Deus produz a si mesmo.

Daí que a determinação do finito se dê pela necessidade da natureza divina. Com efeito, diz a proposição 26: "Uma coisa determinada a operar algo, assim foi determinada necessariamente por Deus; e uma coisa que não foi determinada por Deus não pode determinar-se a si mesma a operar" (Ibid., p. 91). A demonstração parte do caráter positivo de qualquer causa de determinação. Sendo um positivo, deve incluir-se na infinidade de coisas que decor- 
rem da necessidade da natureza divina como de sua causa eficiente (proposição 16). Portanto, mesmo que através de modificações, as coisas singulares, bem como tudo mais, são determinadas por Deus. Evidentemente, ela também não poderá determinar-se a si mesma, a não ser enquanto concebida em Deus, pois do contrário seria ou algo negativo, ou então contradiria a proposição 16, ou por fim seria causa de si, visto que tudo que é, é em si ou em outro (axioma 1), concebido por si ou por outro, não podendo haver causas não causadas. Como as três hipóteses são impossíveis, tudo é necessariamente determinado por Deus.

A proposição 27 ("Uma coisa determinada por Deus a operar algo não pode tornar-se a si mesma indeterminada" [Ibid., p. 91]) é o complemento necessário da proposição anterior. Se Deus é causa de toda determinação e, consequentemente, uma coisa não pode determinar-se a si mesma, resta verificar se ao menos ela pode tornar-se indeterminada. A lacônica demonstração apela para o axioma 3 - "De uma causa determinada dada segue necessariamente um efeito, e inversamente, se nenhuma causa determinada é dada, é impossivel que o efeito siga" (Ibid., p. 47) -, o que revela uma mudança de acento do filósofo quanto à determinação. O acento não recai sobre "ser determinado por", como na proposição anterior, mas sobre "ser determinado a". Como Espinosa acabara de demonstrar que a coisa não pode se determinar sem Deus, logo é evidente que a possibilidade de tornar-se indeterminada não significa tornar-se autodeterminada, ou espontânea, em contraste com uma situação anterior de coação. Não há espontaneidade sem Deus, logo tornar-se indeterminado significa não produzir seus efeitos necessários. Em outras palavras, a hipótese contrariaria duplamente o axioma 3 , ou seja, libertando-se da determinação divina torna-se um efeito sem causa (o que nega a segunda parte do axioma), e renunciando a produzir seus efeitos torna-se uma causa sem efeitos (o que nega a primeira parte). Em resumo, a determinação deverá ser completa e universal. 
Com isso chegamos à proposição 28, uma das mais complexas da Ética:

Todo singular, ou seja, toda coisa que é finita e tem existência determinada, não pode existir nem ser determinado a operar se não for determinado a existir e operar por uma outra coisa, que também é finita e tem existência determinada; e, por sua vez, esta causa não poderá tampouco existir, nem ser determinada a operar, se não for determinada por outra, que também é finita e tem existência determinada; e assim ao infinito. (Ibid., p. 93)

A demonstração começa situando a proposição no movimento das duas anteriores, a saber, na determinação divina universal e na impossibilidade de indeterminação. Dado o finito (e Espinosa não questiona aqui sua origem, mas parte de sua existência como dada), é certo que ele não pôde ser produzido pela natureza absoluta de um atributo. De fato, a proposição 21 demonstrara o absurdo que decorreria disso, a saber, o atributo tornado finito seria uma contradição. Logo, o finito deveu seguir de Deus ou de um atributo enquanto considerado afetado por uma modificação que seja finita e tenha existência determinada (pois, se fosse modificada infinitamente, haveria novo absurdo). Essa modificação, por sua vez, também deveria ter sido determinada por uma outra finita e com existência determinada, e assim sempre ao infinito. O fundamental para nós, nesta demonstração, é mostrar que a determinação divina universal trazida pelas proposições anteriores se estrutura em uma rede causal infinita. A imanência das coisas em relação a Deus não implica uma indiferenciação generalizada, mas, ao contrário, como se traduz em causalidade eficiente imanente, seu existir é uma ação diferenciadora infinita que abrange o infinito e o finito, garantindo a necessidade absoluta de todos os elos da cadeia.

Isso que podemos chamar de completude necessária do real será abordado na proposição 29, onde se demonstrará que "na natureza das coisas nada é dado de contingente, mas tudo é determinado pela necessidade da natureza divina a existir e operar de maneira 
certa" (Ibid., p. 95). O papel da imanência nessa expulsão do contingente deixa-se ver ao analisarmos com mais cuidado a demonstração. Logo de início, Espinosa evoca (pela proposição 15 [Ibid., p. 67]) a imanência das coisas a Deus, ente cuja necessidade já fora demonstrada pelas provas de existência divina apresentadas na proposição 11 (Ibid., p. 59), que não vamos retomar aqui. Por ser Deus necessariamente existente, está demonstrado que necessariamente existem as coisas imanentes a ele, mas não que sejam também causas de si, pois, como modos, não têm sua existência implicada pela própria essência. Como o filósofo dirá mais à frente, no escólio 1 da proposição 33, "Uma coisa é dita necessária ou em razão de sua essência ou em razão de sua causa. Com efeito, a existência de uma coisa segue necessariamente ou de sua própria essência e definição, ou de uma dada causa eficiente" (Ibid., p. 103). Logo, as coisas que são em Deus, sem serem causas de si, devem existir necessariamente por uma outra causa, cujo conhecimento lhes garantirá uma inteligibilidade que a mera demonstração de que "Deus existe" e "tudo é em Deus" não garantia. Em outras palavras, se a necessidade da existência de Deus implica a existência necessária das coisas imanentes, nem por isso explica por que e como tais coisas a ele imanam. É por isso que o filósofo retoma a infinidade dos efeitos de Deus como causa eficiente infinita (proposição 16), o que comprova o recurso à causalidade eficiente imanente para demonstrar a necessidade universal.

De uma definição dada decorrem necessariamente propriedades, e tantas mais quanto a essência da coisa envolve mais realidade ou atributos. Sem evocar nenhuma proposição ou axioma anterior, a proposição 16 apenas verificava que uma infinidade de coisas segue da definição de Deus, assim como as propriedades do círculo decorrem de sua essência, mesmo que não a constituam. Ora, a essência de Deus como causa eficiente é a própria ação dos atributos divinos. Destes decorrem infinitas coisas em infinitos modos, seja enquanto a natureza divina é considerada absolutamente (o que gera os modos infinitos) ou enquanto é determina- 
da a agir de maneira precisa (gerando modos finitos). Em ambos os casos, é o tipo de ação dos atributos, absoluta ou determinada, que produzirá a totalidade dos modos. Em outras palavras, como o movimento que constitui o círculo gera, pela mesma força, as propriedades necessárias deste, assim também a causa de si envolve a existência e pela mesma ação causa todos os modos finitos e infinitos, sempre com absoluta necessidade.

A demonstração da proposição 29, todavia, não para por aí. Demonstrada a necessidade universal da existência das coisas, é preciso passar à necessidade das operações delas. Dada a imanência de Deus às coisas, a contingência das operações destas contaminaria a causa de si, limitando a infinitude de sua potência. Daí a necessidade de evocar a proposição 26 , onde se demonstra que uma coisa determinada a operar o é necessariamente por Deus, sendo impossível, e não contingente, que se autodetermine sem Deus; e também a proposição 27 , onde se demonstra que, uma vez determinada por Deus, é impossível, e não contingente, que a coisa se torne indeterminada. Com efeito, a lógica causal do axioma 3 ("de uma causa determinada dada segue necessariamente um efeito; e, ao contrário, se nenhuma causa determinada for dada é impossivel que siga um efeito" [Ibid., p. 47]) é o que garante a inteligibilidade do real e também o que exclui o contingente, tal como compreendido pela tradição, reduzindo-o ao impossível. Afinal, não há potência de contrários se de toda causa dada segue necessariamente o efeito determinado, inexistindo causas sem efeito ou efeitos sem causa. Isso significa que não se pode anular a ação da causalidade imanente, mesmo na esfera prática, de maneira que a liberdade não poderá mais ser pensada como indiferença ou indeterminação.

Por fim, comprovada a necessidade tanto da existência como das operações de todas as coisas, Espinosa pode dar por concluída a demonstração da proposição 29, bem como a exclusão do contingente. E antes mesmo do exame da vontade, que se dará nas proposições subsequentes, já se pode considerar delineada a 
chamada ontologia do necessário. Afinal Espinosa já esgotou o espaço para a contingência ao apresentar, em todos os seus desdobramentos, a causalidade imanente que tudo determina. Daí que o livro I da Ética possa culminar na identificação entre essência e potência divinas, não como uma exigência extraída do modelo matemático (como foi nossa estratégia aqui), mas como resultado do percurso expansivo da causa de si subjacente a toda a dedução operada no livro.

Referências bibliográficas

ARISTOTE. Organon, Les Seconds Analytiques. Trad. J. Tricot. Paris: Vrin, 1962. Physique. Trad. Henri Carteron. Paris: Les Belles Lettres, 1961.

CHAUI, M. A Nervura do Real. 2 vols. São Paulo: Companhia das Letras, 1999.

DESCARTES, R. Oeuvres philosophiques. v. 2. ed. Alquié, Paris: Gallimard, 1999.

ESPINOSA, B. Ética. Tradução coletiva do Grupo de Estudos Espinosanos da USP. São Paulo: EDUSP, 2015. . Tratado da Correção do intelecto. Trad. Carlos Lopes de Mattos. In: Os Pensadores. São Paulo: Abril Cultural, 1973. 